\title{
Los medios de comunicación como protagonistas de las Relaciones Públicas
}

\author{
PALOMA SANZ-MARCOS \\ Universidad de Sevilla \\ Departamento de Comunicación \\ Audiovisual y Publicidad \\ palomasanz@us.es \\ ORCID: http:Y/orcid.org/0000-0002-6103-6993 \\ D.O.I.: http://dx.doi.org/10.12795/JDU.2018.i01.83 \\ Pp.: 1478-1494
}

\section{Resumen:}

Esta comunicación tiene como objetivo aplicar el segundo ciclo de mejora planteado para el Curso General de Docencia Universitaria. El tema principal, desarrollado en la asignatura Teoría y Estructura de las Relaciones Públicas (RRPP) de primer curso del Grado de Publicidad y RR.PP, es presentar los medios de comunicación, sus características e intereses para trabajar en el ámbito concreto de las relaciones públicas. La innovación ensayada propone una actividad de role play en la que los alumnos deben organizar una rueda de prensa que luego llevan a cabo en la práctica. Los resultados obtenidos tras el análisis comparativo de las herramientas de evaluación inicial y final, reflejan que, en efecto, la aplicación de este ciclo ha supuesto una mejora para el aprendizaje del alumnado. 
Palabras clave: Teoría y Estructura de las Relaciones Públicas; Grado en Publicidad y RR.PP; Docencia Universitaria; Experimentación Docente Universitaria; Relaciones Públicas.

\section{Descripción del contexto}

Esta comunicación se plantea como objetivo presentar y analizar la experiencia del ciclo de mejora implantado para la asignatura Teoría y Estructura de las Relaciones Públicas, obligatoria del primer curso del Grado en Publicidad y RR.PP y de 6 créditos. La idea del ciclo en cuestión parte de la experiencia y actividades de las sesiones del Curso General de Docencia Universitaria y, en concreto, se aplica en los estudiantes del centro EUSA, adscrito a la Universidad de Sevilla. Los estudiantes comienzan por primera vez su experiencia universitaria y constituyen una clase de 32 alumnos.

\section{Diseño previo del Ciclo de Mejora Docente}

El diseño de este ciclo de mejora se inicia con el planteamiento de los contenidos a desarrollar, organizados en forma de mapa. Este mapa viene a clarificar y ordenar toda la materia que se empleará durante el citado ciclo. La temática en cuestión se enfoca en la importancia que tienen los medios de comunicación para la actividad que llevan a cabo los relacionistas públicos (Seitel, 2002; Soler, 1997). Este bloque conceptual es muy necesario para conocer el desarrollo óptimo del trabajo de un relacionista público dado que los medios de comunicación son importantes protagonistas en su tarea diaria. Como se puede observar en el mapa, el ciclo se desarrollará en torno a un gran problema: ¿Cómo se relacionan los agentes de RR.PP con los medios de comunicación? Para tratar de resolver este gran problema, se plantean tres grandes preguntas que bien 
podrían entenderse como mini problemas que tratan de aportar soluciones al gran problema inicial. Cabe destacar que estas preguntas mantienen una estrecha relación entre sí. En este sentido, la interacción entre los contenidos se hace esencial dado que trata de ofrecer una interrelación que se supone óptima desde el punto de vista psicológico del alumno (Porlán, 2017), para que éste adquiera un aprendizaje significativo.

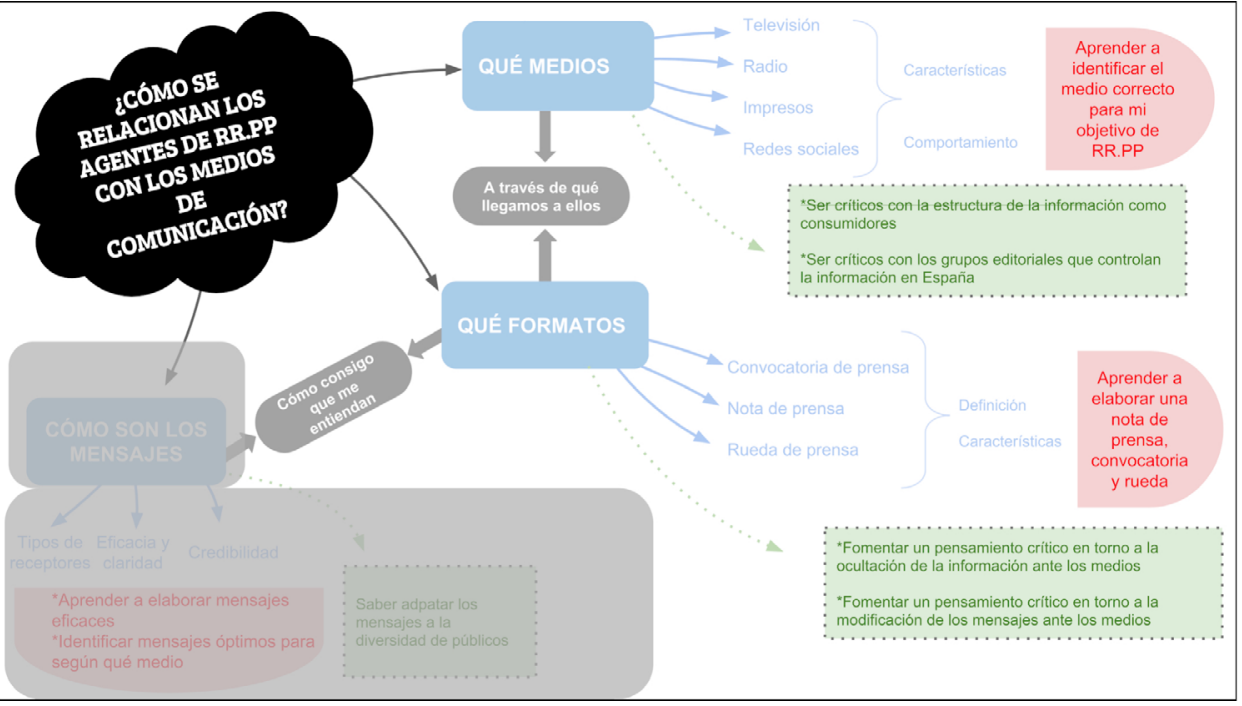

Figura 1. Mapa de contenidos

El mapa consta de tres grandes bloques, que se distinguen en el mapa usando colores diferentes. En azul, vemos los contenidos de tipo conceptual. Estos contenidos son los que normalmente se imparten de manera magistral clásica, es decir, con un modelo metodológico fundamentalmente transmisivo. Como ejemplo de este tipo de contenido, encontramos el dedicado a conocer las características y comportamiento de los medios impresos. Estos conceptos son fundamentalmente de tipo teórico y su explicación se tratará de complementar con el planteamiento de preguntas y la propuesta de actividades que se relacionen e intercalen con el contenido más denso y teórico. Luego, en rojo, tenemos los contenidos de tipo 
procedimental, los cuales vienen a poner en práctica los contenidos conceptuales. Ejemplo de ello es saber elaborar una nota de prensa, la cual se hace a través de una actividad práctica grupal. Finalmente, en verde, encontramos los contenidos de tipo actitudinal, tales como el sentido crítico, que se preende desarrollar a partir de los conceptos que se ven en la asignatura. De alguna manera, el objetivo de estos contenidos es reflexionar en torno al ámbito deontológico de la profesión del relacionista público.

En el mapa aparecen sombreados una serie de contenidos relacionados con este ciclo de mejora pero que, debido a cuestiones de tiempo, no se implementarán para este caso. La decisión de reflejarlos pasa por dar coherencia a la integración de los contenidos de la asignatura y, en concreto, al tema.

\section{Cuestionario inicial-final}

Para valorar el estado de la clase con respecto a este mapa conceptual, es decir, para conocer a priori qué dominio tiene la clase en torno a estos conceptos, hemos diseñado un cuestionario inicial que será la primera "actividad" que le plantearemos a los alumnos. Este cuestionario está compuesto por 5 preguntas que parten directamente de los 3 grandes bloques conceptuales que se piensan tratar durante el ciclo de mejora.

\section{CUESTIONARIO INICIAL DE 20 CICLO DE MEJORA - ASIGNATURA TEORÍA Y ESTRUCTURA DE LAS RR.PP}

1. ¿Son importantes los medios de comunicación para los relacionistas públicos? Justifica tu respuesta, da argumentos.

2. Imagina que necesitas comunicar una información urgente sobre un hecho que ocurre en la 
empresa para la que trabajas, ¿cómo la comunicarías para llegar al máximo número de personas posible?

3. ¿Crees que el relacionista público necesita dominar técnicas de redacción?

4. ¿Opinas que para creer en un mensaje es necesario confiar en el emisor que la lanza?

5. ¿influye el contexto en la recepción de un mensaje?

Las preguntas parten de estos bloques y tratan de no plantear directamente los contenidos que se verán en clase. Se trata de conocer qué conocimientos previos tienen los alumnos para después de aplicar el ciclo, saber qué han aprendido, pues este mismo cuestionario inicial se planteará cuando hayan acabado todas las actividades teóricas y prácticas.

\section{Modelo metodológico posible}

Para promover el aprendizaje de los contenidos presentados en el mapa anterior, se ha diseñado el modelo metodológico que consideramos posible en este momento (ver Figura 2).

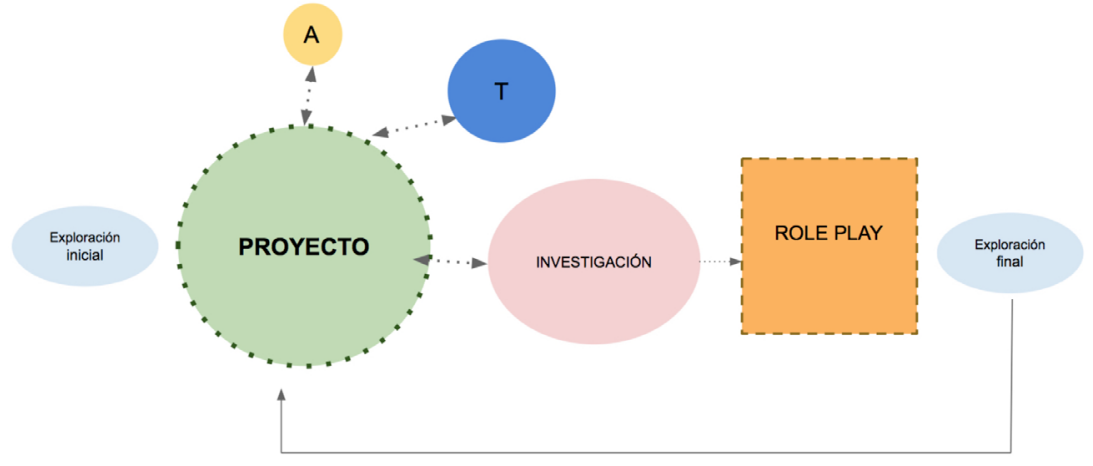

Figura 2. Modelo metodológico posible

Se trata de un modelo metodológico cercano al modelo basado en la indagación, en el cual se entiende el 
aprendizaje como una reelaboración del conocimiento. De este modo, se plantea como objetivo tratar de ir dejando de lado los modelos más cercanos al transmisivo en el que el papel de la teoría y el profesor son más destacables que el del alumnado. Este modelo trata de situar al alumno en el centro del aprendizaje a través de una metodología que parte de un problema que él mismo tiene que resolver. No obstante, la figura del profesor sigue teniendo cierto peso en tanto a que guía al alumno ofreciéndole el material y las fuentes de información a consultar para resolver el problema. De alguna manera, se trata de hacer una especie de hibridación entre lo que plantea Bain (2004) a través de sus talleres y seminarios y Finkel (2008) con su estilo de dar clase con la boca cerrada. En este sentido, partimos de la idea comentada en el curso GDU de que el alumnado no parte de un conocimiento cero, sino que es probable que disponga de ideas y conocimientos elaborados a partir de su experiencia personal.

Como se puede observar en el esquema visual del modelo metodológico, la metodología se inicia con el ya comentado cuestionario inicial (exploración inicial) que únicamente tendría lugar al comienzo del ciclo de mejora. Tras el cuestionario, se plantearía trabajar a través de un proyecto. La idea sería partir del problema comentado anteriormente en el mapa conceptual. El proyecto en cuestión versaría sobre cómo mejorar la imagen deteriorada de las empresa Deloitte tras el incendio sufrido en uno de sus edificios, en este caso, el edificio Windsor. Se trata de un caso real cuya información hoy en día sigue siendo limitada. A día de hoy no ha trascendido de manera clara lo ocurrido y esto ofrece una magnífica oportunidad para poner en evidencia la difícil relación que se puede establecer entre una empresa y los medios de comunicación. La idea es trabajar en cómo podríamos mejorar esa imagen ante los medios de comunicación. Para trabajar en el proyecto se llevarán a cabo tanto actividades de clase como clases magistrales tradicionales. Se plantearán preguntas 
de investigación que habrá que resolver a través de la búsqueda de información y que se fijarán a través de actividades prácticas a realizar en clase. Llegados a este punto, se supone que el alumno ya ha recibido todo el material conceptual para seguir avanzando en uno de los últimos pasos, el role play, que consistirá en realizar una convocatoria de prensa, un dossier de prensa y una rueda de prensa en la que la empresa Deloitte se enfrente a las posibles preguntas de los medios de comunicación. Finalmente, este diseño metodológico acaba con la realización del cuestionario inicial nuevamente (exploración final) que únicamente tendrá lugar el último día del ciclo de mejora.

En definitiva pienso que este modelo contribuiría a un aprendizaje útil y significativo para el alumno, sería divertido para la docente y además tendría una aplicación y relación directa con la realidad y los conceptos teóricos.

\section{Secuencia de actividades}

En el siguiente esquema se presenta el diseño detallado de las actividades, indicando la temporalización y secuenciación de las mismas.

Tabla 1. Secuencia de actividades

\begin{tabular}{|c|c|c|c|c|}
\hline \multicolumn{5}{|c|}{ Día 1(2h) } \\
\hline $\begin{array}{c}\text { Pregunta } \\
\text { relativa al } \\
\text { mapa de } \\
\text { contenidos }\end{array}$ & $\begin{array}{c}\text { Tipo de } \\
\text { actividad }\end{array}$ & $\begin{array}{c}\text { Referencia } \\
\text { al modelo } \\
\text { metodológico }\end{array}$ & Descripción & Tiempo \\
\hline & 1. Calentamiento & & $\begin{array}{c}\text { Se saluda, recapitula } \\
\text { lo del día anterior, se } \\
\text { inicial }\end{array}$ & $10^{\prime}$ \\
& & $\begin{array}{c}\text { comara la clase para } \\
\text { la clase }\end{array}$ & \\
\hline
\end{tabular}

Jornadas de Formación e Innovación Docente del Profesorado I № 1 (2018) Esta obra se distribuye con la licencia Creative Commons 


\begin{tabular}{|c|c|c|c|c|}
\hline & $\begin{array}{l}\text { 2. Cuestionario } \\
\text { inicial }\end{array}$ & $\begin{array}{l}\text { Exploración } \\
\text { inicial }\end{array}$ & $\begin{array}{l}\text { Se advierte de que se } \\
\text { va a trabajar de un } \\
\text { modo diferente las si- } \\
\text { guientes semanas y se } \\
\text { pasa el cuestionario }\end{array}$ & $30^{\prime}$ \\
\hline $\begin{array}{l}\text { Pregunta ge- } \\
\text { neral inicial: } \\
\text { ¿Cómo se re- } \\
\text { lacionan los } \\
\text { agentes de } \\
\text { las RR.PP con } \\
\text { los medios } \\
\text { de comuni- } \\
\text { cación? }\end{array}$ & $\begin{array}{l}\text { 3. Planteamiento } \\
\text { de proyecto }\end{array}$ & PROYECTO & $\begin{array}{l}\text { Se plantea el caso } \\
\text { Windsor. Se explica } \\
\text { qué pasó, se hace un } \\
\text { sondeo con preguntas } \\
\text { cuyas respuestas se } \\
\text { van incluyendo en la } \\
\text { pizarra acerca de qué } \\
\text { harían bajo el nom- } \\
\text { bre de la empresa para } \\
\text { mejorar la imagen (de } \\
\text { manera muy inicial) }\end{array}$ & $45^{\prime}$ \\
\hline $\begin{array}{c}\text { ¿Qué } \\
\text { medios? } \\
\text { Caracterís- } \\
\text { ticas y com- } \\
\text { portamiento } \\
\text { de los me- } \\
\text { dios televi- } \\
\text { sión, radio, } \\
\text { impresos y } \\
\text { rr.ss } \\
\end{array}$ & $\begin{array}{l}\text { 4. Explicación } \\
\text { teórica }\end{array}$ & $\mathrm{T}$ & $\begin{array}{l}\text { El resto de la clase se } \\
\text { dedica a plantear los } \\
\text { primeros conceptos } \\
\text { del primer bloque del } \\
\text { mapa de contenidos }\end{array}$ & $35^{\prime}$ \\
\hline \multicolumn{5}{|c|}{ Día 2 (2h) } \\
\hline & $\begin{array}{l}\text { 1. Calentamiento } \\
\text { inicial }\end{array}$ & & $\begin{array}{c}\text { Se saluda, recapitula } \\
\text { lo del día anterior, se } \\
\text { prepara la clase para } \\
\text { comenzar el silencio y } \\
\text { la clase }\end{array}$ & $10^{\prime}$ \\
\hline $\begin{array}{l}\text { Característi- } \\
\text { cas del me- } \\
\text { dio impreso }\end{array}$ & $\begin{array}{l}\text { 2. Actividad pu- } \\
\text { blicity. Hacer una } \\
\text { acción de publi- } \\
\text { city en el medio } \\
\text { impreso. }\end{array}$ & & $\begin{array}{l}\text { Se plantea una activi- } \\
\text { dad a realizar en clase } \\
\text { acerca de los conteni- } \\
\text { dos vistos en la clase } \\
\text { anterior. La profesora } \\
\text { da la clase con la boca } \\
\text { cerrada y es la guía del } \\
\text { proceso para resolver } \\
\text { la actividad }\end{array}$ & $50^{\prime}$ \\
\hline
\end{tabular}

Jornadas de Formación e Innovación Docente del Profesorado | № 1 (2018) Esta obra se distribuye con la licencia Creative Commons Reconocimiento-NoComercial-SinObraDerivada Internacional (CC BY-NC-ND 4.0.) 


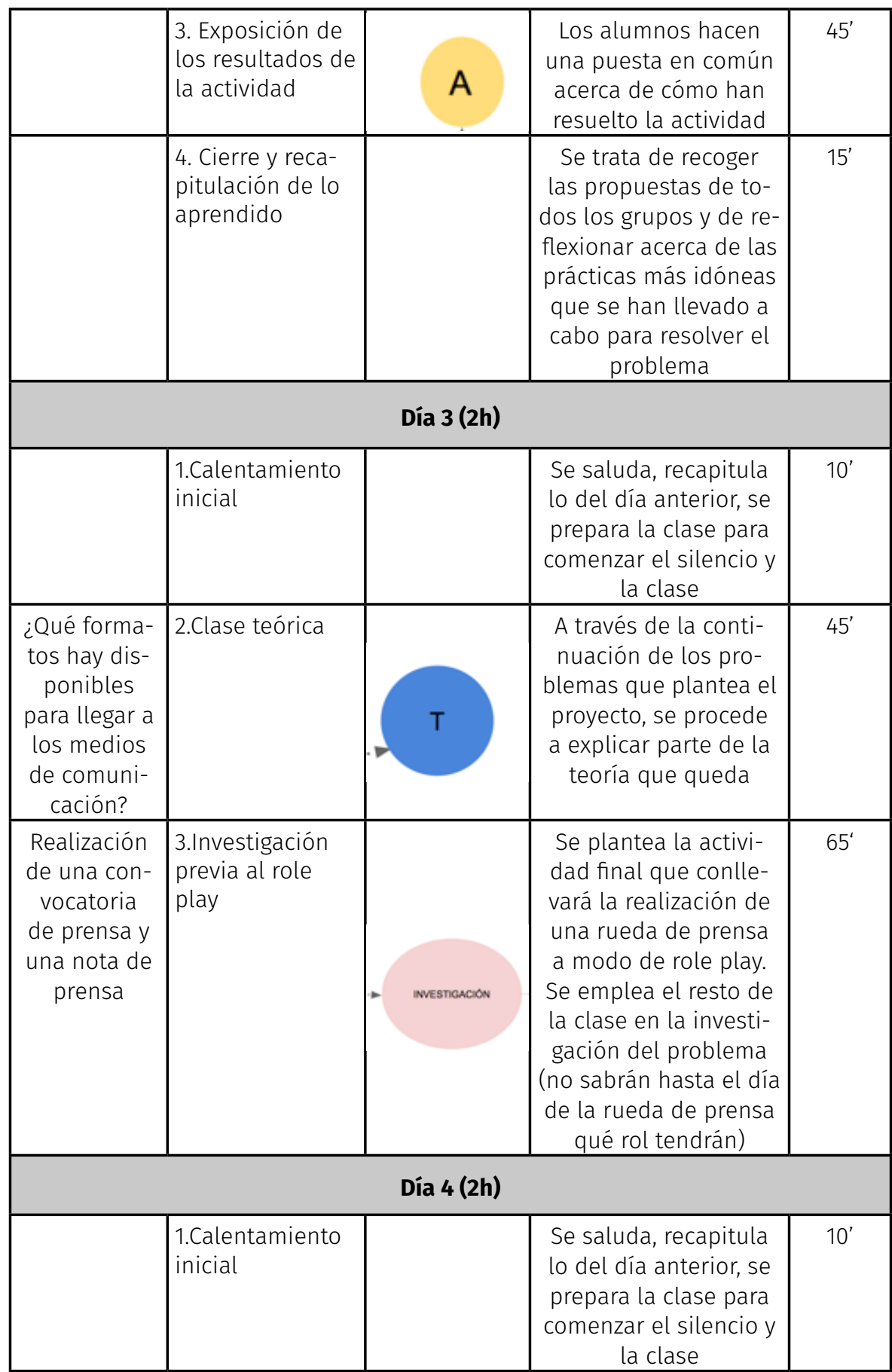

Jornadas de Formación e Innovación Docente del Profesorado | № 1 (2018) Esta obra se distribuye con la licencia Creative Commons Reconocimiento-NoComercial-SinObraDerivada Internacional (CC BY-NC-ND 4.0.) 


\begin{tabular}{|c|c|c|c|c|}
\hline \multirow[t]{4}{*}{$\begin{array}{c}\text { Realización } \\
\text { de una rueda } \\
\text { de prensa }\end{array}$} & $\begin{array}{l}\text { 2.Selección de } \\
\text { los participantes } \\
\text { del role play }\end{array}$ & & $\begin{array}{l}\text { Se seleccionan los par- } \\
\text { ticipantes a través de } \\
\text { ofrecimiento de volun- } \\
\text { tarios y se dispone la } \\
\text { clase para realizar la } \\
\text { rueda de prensa }\end{array}$ & $10^{\prime}$ \\
\hline & $\begin{array}{l}\text { 3.Desarrollo de } \\
\text { role play }\end{array}$ & & $\begin{array}{c}\text { Desarrollo de la rueda } \\
\text { de prensa }\end{array}$ & $45^{\prime}$ \\
\hline & 4.Cierre teórico & $\mathrm{T}$ & $\begin{array}{c}\text { Resolución de du- } \\
\text { das, comentarios y re- } \\
\text { flexión con respecto a } \\
\text { lo ocurrido }\end{array}$ & $30^{\prime}$ \\
\hline & $\begin{array}{l}\text { 5.Cuestionario } \\
\text { final }\end{array}$ & & $\begin{array}{l}\text { Realización del cues- } \\
\text { tionario final y re- } \\
\text { flexión en voz alta } \\
\text { acerca de si ha habido } \\
\text { algún cambio con res- } \\
\text { pecto al primer día }\end{array}$ & $25^{\prime}$ \\
\hline
\end{tabular}

\section{Aplicación del CMD}

\section{Sesión 1}

La primera de las sesiones de este ciclo se desarrolla sin mayor problema. Comenzamos la clase hablando de la importancia de la innovación docente y explico al alumnado que me encuentro inmersa en una etapa de aprendizaje y que, de alguna manera, voy a experimentar con ellos un ciclo de mejora. En este punto me abro con ellos en lo emocional y me sincero expresando lo feliz que me hace poder dar clases en la universidad y poder participar en un curso que me motiva para probar nuevas prácticas. La conversación deriva un largo rato hacia las vocaciones y las profesiones del futuro. Se hace muy gratificante. Nos ponemos manos a la obra haciendo el cuestionario inicial, que se desarrolla rápido y sin complejidad. Una vez que acaba, se comienza a plantear y desvelar un poco el 
proyecto sobre el que vamos a trabajar. Para ello, se plantean dudas acerca del problema del caso Windsor. Se les pregunta a los alumnos que harían y se hace un debate que, en un principio cuesta que arranque, pero que, gracias a las orientaciones de la profesora, se convierte en una interesante charla que plantea más preguntas y temas. Se les explica a continuación que trabajaremos en ello y cómo lo haremos y se pasa a comentar la teoría inicial.

\section{Sesión 2}

Esta sesión es mucho más teórica que la anterior, se comienza retomando lo visto el día anterior y se continúa con la explicación de una de las herramientas usadas en los medios de comunicación, la estrategia de publicity. La explicación se extiende un poco más de lo esperado puesto que se trata de una estrategia que suele presentar ciertas dificultades, y posteriormente la profesora propone la actividad 2 de la sesión 2 que consiste en hacer una campaña de publicity para la marca de bebida Aperol y que tiene como objetivo clarificar las ideas vistas en clase. Durante el trabajo en clase, la profesora va pasando por cada grupo para resolver dudas y orientar al alumnado. De vez en cuando se dan momentos de resolución de ideas en voz alta puesto que muchos grupos tienen las mismas dudas. Una vez se ha pasado el tiempo propuesto para resolver la actividad, los grupos exponen brevemente qué han hecho. No da tiempo a que expongan todos los grupos debido a que algunas exposiciones suscitan comentarios y críticas constructivas que entusiasman a los alumnos y enriquecen la teoría. Como ejemplo me gustaría comentar una campaña muy creativa, pero también poco factible, de una campaña de publicity que consistía en tratar de cambiar la bebida oficial de la feria de Sevilla al vermut. Suscitó muchos comentarios y también muchas risas que hicieron que el ambiente se relajara mucho. 


\section{Sesión 3}

Para no perder tiempo, esta sesión se inicia con las exposiciones que quedaban pendientes. A continuación, se sigue con la teoría. En este caso, se comentan y explican cuestiones clave para la resolución de la actividad importante que vendrá a continuación, es decir, el role play. Se tarda más de lo previsto en las explicaciones y, cuando se acaban, se comienza a trabajar en la actividad 3 de la sesión 3. Aquí se dio una situación curiosa. Dado que el caso es bastante complejo, a medida que comenzaron a trabajar, fueron notando que necesitaban más información y que el caso era difícil de resolver. Esto hizo que tuviéramos que recordar lo importante que es para el relacionista público identificar las prioridades y reflejar una buena imagen. Antes de finalizar la clase da tiempo a configurar los grupos y a explicar y repartir las tareas para la consecución del role play.

\section{Sesión 4}

La clase comienza con el recordatorio de la dinámica y con la resolución de las posibles dudas. A continuación se sortean los principales participantes (algo que no sientan bien a algunos que hubieran querido participar pero que no han podido). No obstante, se motivan muchos los alumnos y consiguen del departamento de medios micrófonos para simular la rueda de prensa. Se disponen las mesas y las sillas para simular una rueda de prensa verdadera y comienza a desarrollarse el role play. Este momento se hace crucial, se hace el silencio y se notan caras de nervios. Parece que la disposición de las mesas y la aparición de los micrófonos, hacen que se metan de lleno en el papel. Una vez se inicia la dinámica, sorprenden lo bien que sale el role play con la salvedad de algunas cuestiones referidas a algunos de los participantes que al comienzo se ponen algo nerviosos. Por lo demás, surge una dinámica muy divertida y que, dados los comentarios y las 
preguntas planteadas, refleja que, los alumnos se han enterado de al menos lo más importante de los contenidos previstos para esta actividad. Cabe destacar que, a medida que se hacen las exposiciones, la profesora va haciendo anotaciones en la rúbrica que después tendrá que retomar para corregir los dossieres de prensa entregados. Antes de acabar, hacemos lo fundamental para fijar los contenidos: sacamos algunas conclusiones referidas a la manipulación de la información por parte de los medios y algunos comentan que se sienten con una gran responsabilidad desde el punto de vista del rol del relacionista público. Parece que entienden la importancia de su trabajo.

\section{Evaluación del CMD}

Para evaluar este ciclo de mejora se han usado dos instrumentos. Por un lado, se ha empleado el cuestionario inicial y final y se han analizado las respuestas, elaborando sus respectivas escaleras de aprendizaje. En la figura 3 se presenta un ejemplo, representando en blanco y negro las respuestas del cuestionario inicial y en color las del cuestionario final. A modo de comparación, podemos observar que ha habido un cambio significativo en el aprendizaje de los estudiantes.

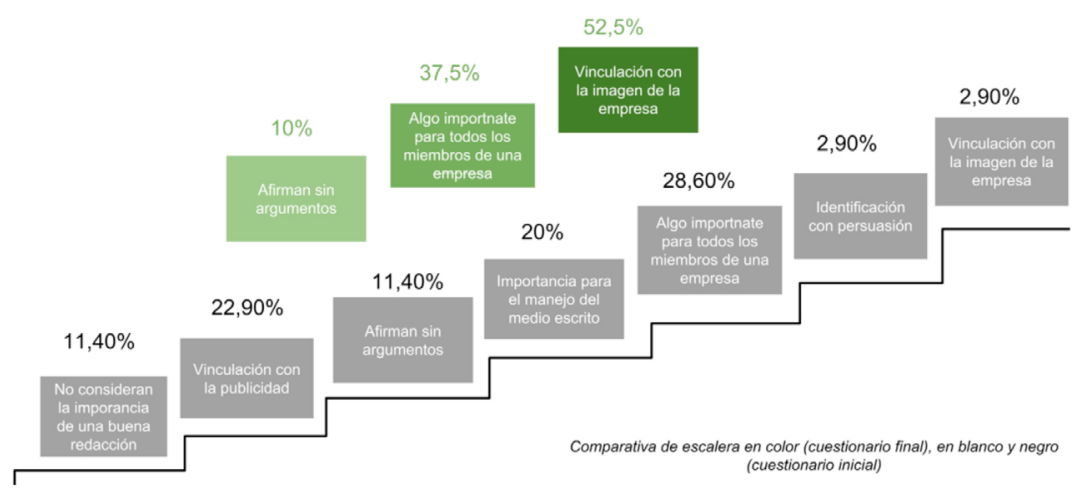

Figura 3. Escalera de aprendizaje comparativa

Jornadas de Formación e Innovación Docente del Profesorado | № 1 (2018) Esta obra se distribuye con la licencia Creative Commons 
Los escalones han disminuido en cantidad debido a la obtención de unas respuestas mucho más rotundas y claras de los estudiantes. Parece que el alumnado comprende que las técnicas de redacción son una función clave para el desarrollo del relacionista público y que no hay lugar para pensar que no sea una función que deban adquirir. Esto refleja que, en efecto, la redacción del dossier de prensa ha supuesto una actividad fructífera para poner en práctica los contenidos teóricos. Da la sensación de que ciertos problemas encontrados, como entender la importancia de la práctica persuasiva a través de la redacción, es considerada ahora por los alumnos como una técnica esencial a dominar.

Por otro lado, se ha empleado una rúbrica (ver Figura 4). Como se observa, contiene también calificación (mediante excel y una fórmula aplicada). La rúbrica pretende ser lo más objetiva posible y contiene tres aspectos fundamentales a evaluar de la actividad final. Para cada uno de ellos se han desglosado una serie de criterios que pretenden ser objetivos alcanzables y deseables para la elaboración tanto del dossier de prensa como de la ejecución del role play. En cuanto a la validez de la rúbrica, se han detectado posibles mejoras que aplicar para el futuro ya que, a medida que se iba desarrollando la actividad, se detectaban algunas cuestiones que no estaban recogidas y que sería interesante tener en cuenta. No obstante, su aplicación ha sido bastante satisfactoria puesto que ha permitido mecanizar y agilizar el trabajo de evaluación de la profesora.

Jornadas de Formación e Innovación Docente del Profesorado I № 1 (2018) Esta obra se distribuye con la licencia Creative Commons 
Tabla 2. Rúbrica de evaluación

GRUPO: $X X X X$

\begin{tabular}{|c|c|c|c|c|}
\hline \multicolumn{5}{|c|}{ DOSSIER DE PRENSA } \\
\hline $\begin{array}{c}\text { Trabajado al } \\
\text { detalle, con- } \\
\text { tiene imá- } \\
\text { genes e } \\
\text { información } \\
\text { verdadera- } \\
\text { mente útil } \\
\text { para el perio- } \\
\text { dista. Factible } \\
\text { y coherente. }\end{array}$ & $\begin{array}{l}\text { A pesar de } \\
\text { no ser minu- } \\
\text { cioso, está } \\
\text { trabajado co- } \\
\text { rrectamente, } \\
\text { es coherente } \\
\text { y factible } \\
\text { para la infor- } \\
\text { mación que } \\
\text { necesita el } \\
\text { periodista. }\end{array}$ & $\begin{array}{l}\text { Contiene in- } \\
\text { formación } \\
\text { que no es } \\
\text { precisa para } \\
\text { el periodista } \\
\text { o pone cues- } \\
\text { tiona la ima- } \\
\text { gen de la } \\
\text { empresa. }\end{array}$ & $\begin{array}{l}\text { Se identifi- } \\
\text { can errores/ } \\
\text { poco facti- } \\
\text { ble/poco de- } \\
\text { tallado/poco } \\
\text { trabajado. }\end{array}$ & \\
\hline 3,5 & 2,66 & 2 & 1,66 & 9,82 \\
\hline $\begin{array}{l}\text { Demuestran } \\
\text { el estudio } \\
\text { previo de la } \\
\text { información } \\
\text { y los hechos. } \\
\text { Están bien } \\
\text { planteadas } \\
\text { y se dirigen } \\
\text { al personaje } \\
\text { correcto. }\end{array}$ & $\begin{array}{c}\text { Son pregun- } \\
\text { tas correctas } \\
\text { y coheren- } \\
\text { tes pero poco } \\
\text { precisas para } \\
\text { recabar la } \\
\text { información. }\end{array}$ & $\begin{array}{l}\text { La mayoría de } \\
\text { las preguntas } \\
\text { que se plan- } \\
\text { tean son de } \\
\text { tipo sensa- } \\
\text { cionalista. }\end{array}$ & $\begin{array}{l}\text { La mayoría } \\
\text { de las pre- } \\
\text { guntas que se } \\
\text { plantean son } \\
\text { de tipo alea- } \\
\text { torio, no de- } \\
\text { muestran } \\
\text { el trabajo } \\
\text { previo de } \\
\text { investigación. }\end{array}$ & \\
\hline 3,5 & 2,66 & 2 & 1,66 & 9,8 \\
\hline \multicolumn{5}{|c|}{ PLANTEAMIENTO DE PREGUNTAS } \\
\hline $\begin{array}{l}\text { Demuestran } \\
\text { el estudio } \\
\text { previo de la } \\
\text { información } \\
\text { y los hechos. } \\
\text { Están bien } \\
\text { planteadas } \\
\text { y se dirigen } \\
\text { al personaje } \\
\text { correcto. }\end{array}$ & $\begin{array}{c}\text { Son pregun- } \\
\text { tas correctas } \\
\text { y coheren- } \\
\text { tes pero poco } \\
\text { precisas para } \\
\text { recabar la } \\
\text { información. }\end{array}$ & $\begin{array}{l}\text { La mayoría de } \\
\text { las preguntas } \\
\text { que se plan- } \\
\text { tean son de } \\
\text { tipo sensa- } \\
\text { cionalista. }\end{array}$ & $\begin{array}{c}\text { La mayoría } \\
\text { de las pre- } \\
\text { guntas que se } \\
\text { plantean son } \\
\text { de tipo alea- } \\
\text { torio, no de- } \\
\text { muestran } \\
\text { el trabajo } \\
\text { previo de } \\
\text { investigación. }\end{array}$ & \\
\hline 3,5 & 2,66 & 2 & 1,66 & 9,82 \\
\hline
\end{tabular}

Jornadas de Formación e Innovación Docente del Profesorado | № 1 (2018) Esta obra se distribuye con la licencia Creative Commons Reconocimiento-NoComercial-SinObraDerivada Internacional (CC BY-NC-ND 4.0.) 
TURNO DE RESPUESTA

\begin{tabular}{|c|c|c|c|c|}
\hline $\begin{array}{l}\text { Se demues- } \\
\text { tra el trabajo } \\
\text { previo de } \\
\text { preparación. } \\
\text { El rol es des- } \\
\text { empeñado } \\
\text { con seguri- } \\
\text { dad y firmeza. } \\
\text { Seriedad y } \\
\text { atención al } \\
\text { resto de los } \\
\text { compañeros. }\end{array}$ & $\begin{array}{l}\text { Se responde } \\
\text { a todo de } \\
\text { manera co- } \\
\text { rrecta pero se } \\
\text { manifiestan } \\
\text { inseguridades } \\
\text { o debilidades } \\
\text { que suelen } \\
\text { ser propias } \\
\text { de una pre- } \\
\text { paración } \\
\text { mediocre. }\end{array}$ & $\begin{array}{c}\text { Se observa } \\
\text { una tónica } \\
\text { generali- } \\
\text { zada basada } \\
\text { en desenten- } \\
\text { derse de la } \\
\text { responsabili- } \\
\text { dad. }\end{array}$ & $\begin{array}{c}\text { Se observa } \\
\text { poca prepara- } \\
\text { ción. Las res- } \\
\text { puestas son } \\
\text { aleatorias y } \\
\text { no se toma } \\
\text { en serio la di- } \\
\text { námica. No se } \\
\text { ha atendido } \\
\text { al resto de } \\
\text { compañeros } \\
\text { durante sus } \\
\text { exposiciones }\end{array}$ & \\
\hline 3,5 & 2,66 & 2 & 0 & 9,82 \\
\hline
\end{tabular}

En cuanto a las cuestiones a mantener y cambios a introducir para un futuro Ciclo de Mejora, creo que en general, la dinámica ha sido muy positiva. Me llevo la grata sensación de que no sólo han podido poner en práctica lo visto en clase, sino que además han podido comprobar que el papel de un relacionista público es esencial a la hora de gestionar la imagen de una empresa. No obstante, hay cosas que trataría de mejorar. En primer lugar, la gestión del tiempo, pues considero que no ha sido adecuada. Quizás, se hubiera necesitado más tiempo para que el alumnado no se hubiera sentido agobiado. Creo que darles mayor margen hubiera supuesto una mejora en la calidad de los dossieres de prensa entregados.

Además, creo que se hace necesario hacer algún cambio en cuanto a los contenidos. No sé si a través del visionado de un documental o video de una práctica profesional concreta, sería conveniente hacerles ver la importancia de la gestión de la información a través de los medios de comunicación en el mundo real. Creo que no son conscientes de la manipulación mediática y esto es muy importante para el trabajo de un relacionista público. En este sentido, se me ha hecho muy dificil hacerles llegar esta idea. No obstante, la puesta en práctica de la rueda de prensa ha 
incidido de manera óptima en la adquisición de conocimientos, puesto que las preguntas y las respuestas de los compañeros denotaban cierta madurez. En definitiva, creo que lo que cambiaría sería el tiempo, lo alargaría. Insistiría en ciertos aspectos teóricos de manera más pausada. Y mantendría en mi práctica habitual seguir haciendo actividades de este tipo que pongan en práctica los conceptos vistos en clase.

\section{Referencias bibliográficas}

Bain, K. (2004). Lo que hacen los mejores profesores universitarios. Valencia: Universitat de Valencia.

Finkel, D. (2008). Dar clase con la boca cerrada. Valencia: Universitat de Valencia.

Porlán, R. (Coord.). (2017). Enseñanza universitaria. Cómo mejorarla. Madrid: Ediciones Morata.

Seitel, F. P. (2002). Teoría y Práctica de las Relaciones Públicas. Madrid: Pearson.

Soler, P. (1997). Estrategias de Comunicación en Publicidad y Relaciones Públicas. Barcelona: Gestión 2000.

Jornadas de Formación e Innovación Docente del Profesorado | № 1 (2018) Esta obra se distribuye con la licencia Creative Commons 